\title{
Extragastroesophageal Malignancy-Associated Secondary Achalasia: A Rare Association of Pancreatic Cancer Rendering Alarm Manifestation
}

\author{
Hong Min Kim, Ji Min Chu, Won Hee Kim, Sung Pyo Hong, Ki Baik Hahm and Kwang Hyun Ko \\ Department of Internal Medicine, CHA Bundang Medical Center, CHA University, Seongnam, Korea
}

Secondary achalasia or pseudoachalasia is a rare esophageal motor abnormality, which mimics primary achalasia; it is not easily distinguishable from idiopathic achalasia by manometry, radiological examination, or endoscopy. Although the majority of reported pseudoachalasia cases are associated with neoplasms at or near the esophagogastric (EG) junction, other neoplastic processes or even chronic illnesses such as rheumatoid arthritis can lead to the development of pseudoachalasia, for example, mediastinal masses, gastrointestinal (GI) tumors of the liver and biliary tract, and non-GI malignancies. Therefore, even if a patient presents with the typical findings of achalasia, we should be alert to the possibility of other GI malignancies besides EG tumors. For instance, pancreatic cancer was found in the case reported here; only four such cases have been reported in the literature. A 47-year-old man was admitted to our center with a 3-month history of dysphagia. His endoscopic and esophageal manometric findings were compatible with primary achalasia. However, unresponsiveness to diverse conventional achalasia treatments led us to suspect secondary achalasia. An active search led to a diagnosis of pancreatic mucinous cystadenocarcinoma invading the gastric fundus and EG junction. This rare case of pseudoachalasia caused by pancreatic carcinoma emphasizes the need for suspecting GI malignancies other than EG tumors in patients refractory to conventional achalasia treatment. Clin Endosc 2015;48:328-331

Key Words: Esophageal achalasia; Pseudoachalasia; Esophagogastric tumor; Pancreatic neoplasms

\section{INTRODUCTION}

Pseudoachalasia is a rare esophageal motility disorder that has clinical and diagnostic features consistent with achalasia. ${ }^{1,2}$ The term "pseudoachalasia" generally applies to a subgroup of less than $5 \%$ of patients presenting with clinical features of achalasia, but in whom an occult malignant tumor is the cause of dysphagia. ${ }^{3}$ Therefore, most of the malignant tumors associated with secondary achalasia are adenocarcinomas of the esophagogastric (EG) junction, which account for more

\footnotetext{
Received: August 4, 2014 Revised: August 10, 2014

Accepted: August 10, 2014

Correspondence: Kwang Hyun Ko

Department of Internal Medicine, CHA Bundang Medical Center, CHA University, 59 Yatap-ro, Bundang-gu, Seongnam 463-712, Korea

Tel: +82-31-780-5214, Fax: +82-31-780-5219, E-mail: bluehipp@cha.ac.kr

(c) This is an Open Access article distributed under the terms of the Creative Commons Attribution Non-Commercial License (http://creativecommons.org/ licenses/by-nc/3.0) which permits unrestricted non-commercial use, distribution, and reproduction in any medium, provided the original work is properly cited.
}

than $70 \%$ of cases. ${ }^{4}$ The remaining cases involve metastatic disease from the surrounding liver, mediastinum, or biliary cancer. Until now, few cases have been reported to be associated with pancreatic cancer. In this type of pseudoachalasia, the mechanisms proposed to explain the clinical features of pseudoachalasia include a circumferential mechanistic obstruction of the distal esophagus or malignant infiltration that destroys inhibitory neurons within the myenteric plexus of the esophageal wall. ${ }^{5,6}$ In our case, pseudoachalasia was caused by a rare pancreatic cancer beyond the EG junction, and the lesson from that was to not consider the EG area or EG junction tumors alone when diagnosing secondary achalasia.

\section{CASE REPORT}

A 47-year-old man was admitted to our hospital with a 3-month history of dysphagia and a resultant $15 \mathrm{~kg}$ weight 

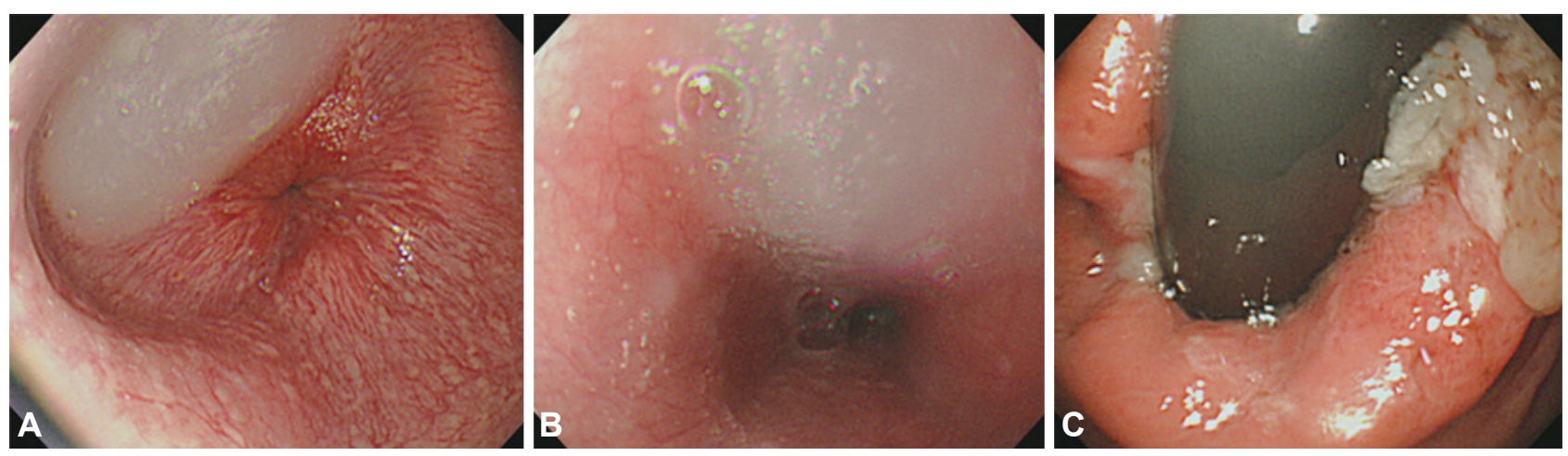

Fig. 1. Esophagoscopic finding suggestive of primary achalasia. A dilated esophagus filled with liquid and some solid foods is visible (A, B), which is compatible with the findings of primary achalasia. There was no evidence of extrinsic compression or any cardiac lesion on retroversion of endoscopy (C).

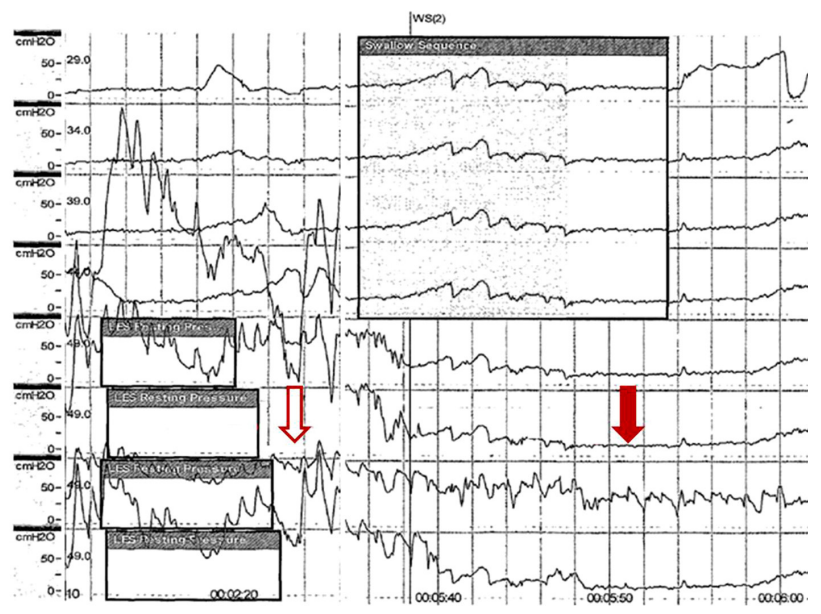

Fig. 2. Esophageal manometry findings suggestive of primary achalasia. Manometry shows a total absence of peristalsis in the body of the esophagus (vacant arrow) and a hypertonic lower esophageal sphincter with incomplete relaxation (filled arrow).

loss in 3 months. The patient did not have any relevant medical history in the previous year, but he had complained of solid food dysphagia at first, which gradually aggravated to liquid food dysphagia. He also experienced intermittent hoarseness. On physical examination, his vital signs were found to be stable and though mild tenderness was found on his epigastrium, there was no palpable mass in the abdomen. To search for the cause of dysphagia, upper endoscopy was performed, revealing some fluid and food contents on the lower esophagus along with a mildly dilated esophagus (Fig. $1 \mathrm{~A}, \mathrm{~B})$; the endoscope met with severe resistance while passing through the EG junction, but the scope could be passed into the stomach (Fig. 1C). On esophageal manometric examination, the pressure of the lower esophageal sphincter was very high, accompanied by a low pressure of the esophageal body and some aperistaltic contractions, which is compatible with achalasia (Fig. 2). Considering the clinical impression of primary achalasia, we injected $0.5 \mathrm{~mL}$ of a solution containing 100 IU botulinum toxin (Botox; Allergan, Irvine, CA, USA) mixed with $2 \mathrm{~mL}$ normal saline into the EG junction in the $3,6,9$, and 12 oclock directions to relive dysphagia (Fig. 3). Failure to improve symptoms with botulinum toxin led us to perform up to $20 \mathrm{~mm}$ through the scope (TTS) esophageal balloon dilatation thrice for 30 seconds each (Cook Tri-Ex; Cook, Duluth, GA, USA) followed by $30 \mathrm{~mm}$ TTS ballooning. Considerable resistance to ballooning, which manifested as inefficiency, led us to obtain a chest/abdominal computed tomography (CT) scan to elucidate other possibilities of secondary achalasia. An abdominal CT scan was performed and revealed a $7.5 \mathrm{~cm}$-sized multiple septated cystic pancreatic mass invading the area from the gastric body to the fundus. Minimal omental infiltration was found in the paracardiac area with some ascites in the pelvic cavity, suggesting peritoneal carcinomatosis (Fig. 4). A tumor tissue biopsy confirmed the diagnosis of pancreatic mucinous cyst adenocarcinoma. Although we placed an esophageal stent (uncovered, $5 \mathrm{~cm}$; Taewoong Medical, Seoul, Korea) to relieve dysphagia (Fig. 5), and additionally administered gemcitabine-based chemotherapy $\left(1,000 \mathrm{mg} / \mathrm{m}^{2}\right.$ bovine serum albumin; Gemzar, Eli-Lilly, IN, USA), the patient died 5 months later.

\section{DISCUSSION}

Pseudoachalasia is an esophageal motility disorder that has clinical, radiographic, and manometric findings indistinguishable from primary achalasia, and is usually associated with EG tumors or other local malignancies. Although the first two cases of secondary, malignancy-induced, achalasia were described by Howarth ${ }^{1}$ early in 1919, the prevalence of pseudoachalasia is not very rare, and is about $2 \%$ to $4 \%$ among patients with manometric findings suggestive of achalasia. ${ }^{2,3,7}$ Very rarely, a distantly located neoplasm may cause pseudoachalasia through a paraneoplastic process and rarely through malignancy- or chronic illness-associated amyloidosis. Pseu- 

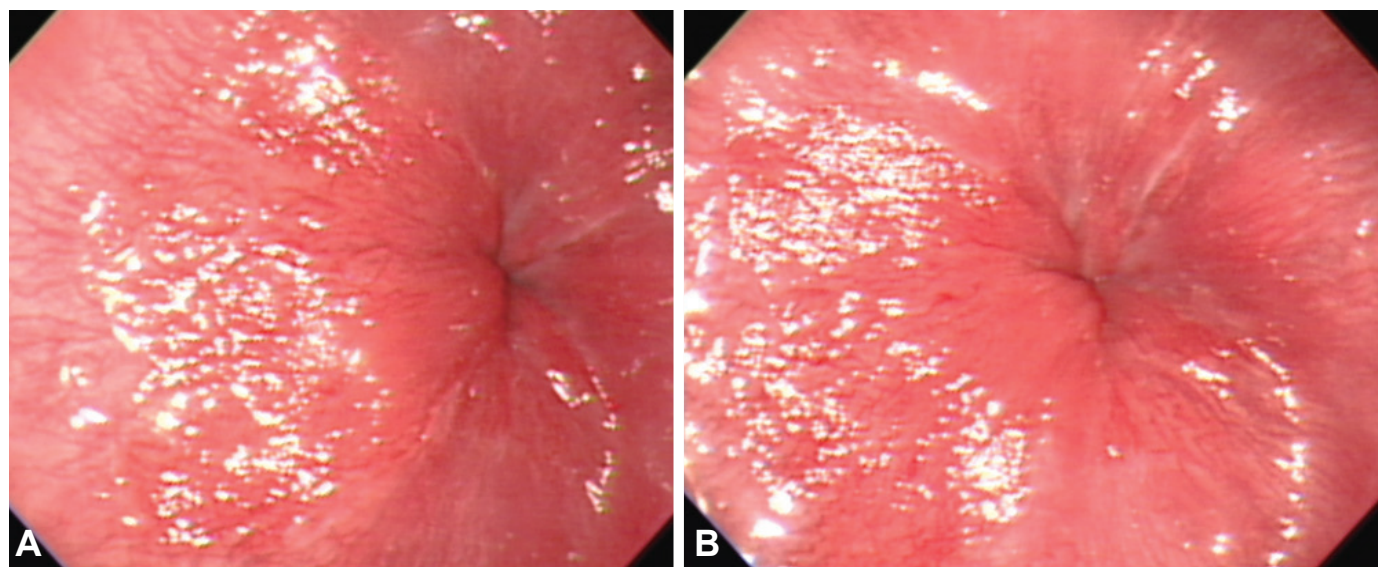

Fig. 3. Botulinum toxin injection therapy to relieve achalasia. In total, $4 \mathrm{~mL}$ of botulinum toxin was injected at four points in the esophagogastric junction with $1 \mathrm{~mL}$ injected at each point. The photographs show the condition of the esophagogastric junction before $(A)$ and after $(B)$ the botulinum toxin injections.

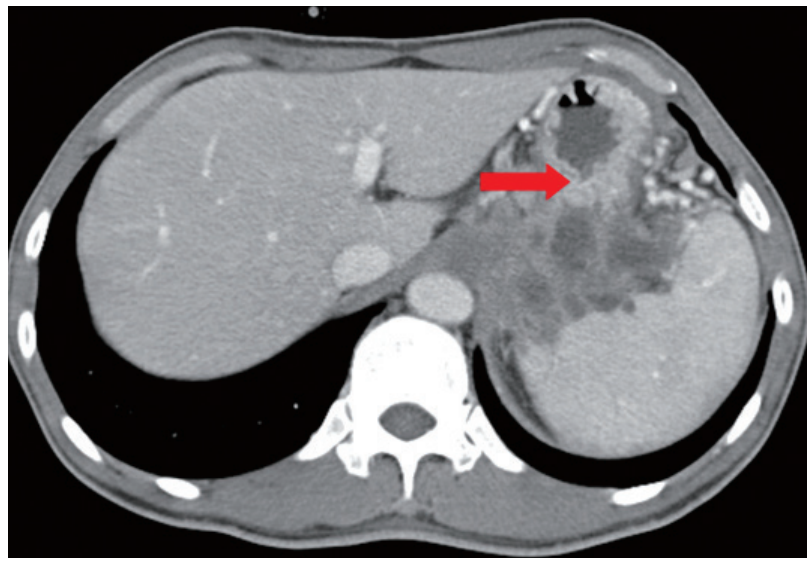

Fig. 4. Abdominal and pelvic computed tomography findings showing a huge mass extending into the gastric fundus. An approximately $7.5-\mathrm{cm}$ sized irregular infiltrative solid mass with multiple septated cystic portions originating from the pancreas had invaded the gastric body and extended to the gastric fundus (arrow).

doachalasia associated with pancreatic cancer, as seen in our case, is a very rare manifestation. Based on the current case report, we would like to highlight that when pseudoachalasia is considered in patients complaining of severe weight loss and dysphagia, pancreatic cancer can also be one of the differential diagnoses. The most common mechanism of pseudoachalasia is direct involvement of neoplastic cells in the esophageal myenteric plexus. The distinguishing feature of secondary versus primary achalasia is the complete reversal of pathologic motor phenomena following successful therapy of the underlying disorder. $^{8}$

Primary malignancy of the EG junction accounts for 54\% to $70 \%$ of pseudoachalasia cases, with adenocarcinomas of the gastric fundus or distal esophagus being the most commonly implicated tumors. ${ }^{3,6,8}$ While many forms of malignancy can metastasize to the esophagus, only $6 \%$ of pseudoachalasia cases are secondary to metastatic versus primary disease. ${ }^{4}$ Differentiation of primary from secondary achalasia has crit-

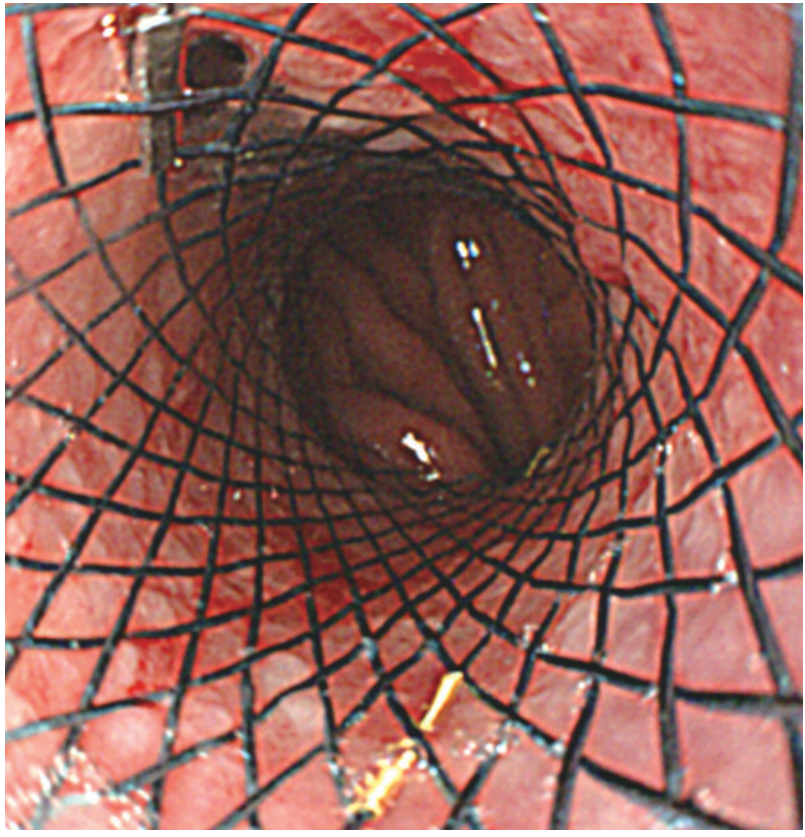

Fig. 5. Esophageal stent insertion to relieve dysphagia of secondary achalasia. Endoscopic image of an esophageal stent (uncovered, $5 \mathrm{~cm}$; Taewoong Medical) placed across the esophagogastric junction into the proximal stomach.

ical implications for patient management because of vastly different approaches for the work-up and treatment of these conditions.

Older age ( $>50$ years), short clinical history ( $<1$ year), and significant weight loss ( $>15$ pounds) in a short period of time are usually considered suggestive of malignancy-associated pseudoachalasia. ${ }^{9,10}$ Although combined clinical criteria can provide a highly sensitive test for secondary achalasia, the low prevalence and similar clinical and radiological presentations of secondary achalasia make these criteria inaccurate in predicting the disease. ${ }^{10}$

The presence of a dilated esophagus on barium swallow examination, and a dilated esophagus filled with food materi- 
als and with a tapered narrowing on endoscopy are common findings in both primary and secondary achalasia, which are very hard to differentiate based on these examinations. The most sensitive test to diagnose primary achalasia is esophageal manometry, typically with incomplete lower esophageal sphincter relaxation and complete aperistalsis of the esophageal body. The presence of peristalsis in some swallows should itself raise the suspicion of pseudoachalasia, but in some cases like ours, complete aperistalsis of the esophageal body cannot discriminate between primary and secondary achalasia at all. Instead, endoscopic ultrasound and CT are useful diagnostic tools to differentiate between secondary and primary achalasia. This was ambiguous in our case as well, but the CT scan clearly suggested pseudoachalasia. A recent study showed that distal esophageal wall thickening that is nodular or lobulated and asymmetric; a soft-tissue mass at the EG junction; mediastinal lymphadenopathy; and pulmonary, hepatic, or osseous metastases are findings that point to secondary achalasia. ${ }^{11}$ In our case, CT scans showed a mediastinal mass originating from the pancreas that compressed the EG junction; invaded the spleen and both diaphragmatic crus; and encased the celiac trunk, common hepatic arteries, splenic vein, and left adrenal gland. Since CT scans are not routinely used in the assessment of primary achalasia, ${ }^{12,13}$ it is very difficult to distinguish primary achalasia from pseudoachalasia using routine examinations; however, we would like to suggest that in patients showing a weak response to conventional achalasia treatment, CT scans should be mandatory in order to exclude the second clinical condition. ${ }^{14}$

In conclusion, we should pay attention to malignant tumors as a cause of secondary achalasia because of the increasing incidence of malignancies. The failure of conventional treatment for primary achalasia, such as medication, botulinum toxin injection, and pneumatic dilation, might suggest the possibility of secondary achalasia. Furthermore, in addition to EG junction malignancy, GI malignancies at other sites should be included in the differential diagnosis. In the literature, only four cases of pseudoachalasia in pancreatic cancer patients have been described until now. ${ }^{15-18}$ Their mean age was 64.75 years, the clinical history was 5.75 months, and weight loss was prominent, typically around $14 \mathrm{~kg}$. The CT scan showed invasion of the EG junction. In this article, we report a case of pseudoachalasia in a middle-aged man with recent onset of symptoms and with substantial weight loss. Esophageal manometric findings typical of achalasia were observed. An abdominal CT scan showed typical features, suggesting secondary achalasia. Although very rare, pseudoachalasia is a clinical condition that should be considered in the differential diagnosis of achalasia in patients presenting with dysphagia. It should be remembered that tumors outside the EG area could also be responsible for secondary achalasia.

\section{Conflicts of Interest}

The authors have no financial conflicts of interest.

\section{REFERENCES}

1. Howarth W. Discussion on dilatation of the oesophagus without anatomical stenosis. Proc R Soc Med 1919;12(Laryngol Sect):64.

2. Tracey JP, Traube M. Difficulties in the diagnosis of pseudoachalasia. Am J Gastroenterol 1994;89:2014-2018.

3. Kahrilas PJ, Kishk SM, Helm JF, Dodds WJ, Harig JM, Hogan WJ. Comparison of pseudoachalasia and achalasia. Am J Med 1987;82:439-446.

4. Paulsen JM, Aragon GC, Ali MA, Brody FJ, Borum ML. Pseudoachalasia secondary to metastatic breast carcinoma. Dig Dis Sci 2010;55:11791181.

5. Bustamante M, Devesa F, Ferrando MJ, Borghol A. Difficulty in the early diagnosis of pseudoachalasia of tumoral origin. Gastroenterol Hepatol 2001;24:144-145.

6. Liu W, Fackler W, Rice TW, Richter JE, Achkar E, Goldblum JR. The pathogenesis of pseudoachalasia: a clinicopathologic study of 13 cases of a rare entity. Am J Surg Pathol 2002;26:784-788.

7. McCallum RW. Esophageal achalasia secondary to gastric carcinoma. Report of a case and a review of the literature. Am J Gastroenterol 1979;71:24-29.

8. Gockel I, Eckardt VF, Schmitt T, Junginger T. Pseudoachalasia: a case series and analysis of the literature. Scand J Gastroenterol 2005;40:378385.

9. Tucker HJ, Snape WJ Jr, Cohen S. Achalasia secondary to carcinoma: manometric and clinical features. Ann Intern Med 1978;89:315-318.

10. Sandler RS, Bozymski EM, Orlando RC. Failure of clinical criteria to distinguish between primary achalasia and achalasia secondary to tumor. Dig Dis Sci 1982;27:209-213.

11. Licurse MY, Levine MS, Torigian DA, Barbosa EM Jr. Utility of chest CT for differentiating primary and secondary achalasia. Clin Radiol 2014;69:1019-1026.

12. Rabushka LS, Fishman EK, Kuhlman JE. CT evaluation of achalasia. J Comput Assist Tomogr 1991;15:434-439.

13. Richter JE. Achalasia: an update. J Neurogastroenterol Motil 2010;16:232-242.

14. Martinez C, Targarona EM, Sainz S, Cerdan G, Novell J, Trias M. Pseudoachalasia: a diagnosis to consider in the assessment of dysphagia. Gastroenterol Hepatol 2000;23:14-15.

15. Portale G, Costantini M, Zaninotto G, et al. Pseudoachalasia: not only esophago-gastric cancer. Dis Esophagus 2007;20:168-172.

16. de Borst JM, Wagtmans MJ, Fockens P, van Lanschot JJ, West R, Boeckxstaens GE. Pseudoachalasia caused by pancreatic carcinoma. Eur J Gastroenterol Hepatol 2003;15:825-828.

17. Pesce A, Scilletta R, Branca A, Portale TR, Puleo S. A rare case of pancreatic cancer presenting as pseudoachalasia. Ann Ital Chir 2012;2012:pii: S2239253X12019627.

18. Kang CJ, Koh KH, Kim DH, et al. A case of pseudoachalasia accompanied by pancreatic cancer. Korean J Neurogastroenterol Motil 2008;14:57-60. 